\title{
Production, translocation et présentation du soi peptidique
}

Les molécules du complexc majeur d'histocompatibilité (CMH) de classe I et de classe II ont pour fonction de présenter les peptides du soi et du non-soi (self, non-self) [1-3]. La compréhension des phénomènes impliqués dans cettc présentation fait actucllement de très rapides progrès. On savait déjà que les peptides doivent, pour se licr aux molécules de classe I, passer la membrane du réticulum cndoplasmique grâce à l'action de transportcurs de peptides dont au moins deux gènes, ham 1 ct ham 2, sont localisés dans le complexe génétique des gènes de classe II $[3,4]$. Trois équipes - allemande [5], amćricainc $[6,7]$ et anglaisc $[4,8]-$ rapportent maintenant que cette région chromosomique conticnt égalcment des gènes codant pour des protéases. Les produits des gènes de protéases détectés apparticnnent à un vastc complexc protéolytique non lysosomial dénommé protćasome, complexc dont l'une des fonctions pourrait être la production des peptides destinés à êtres présentés, après translocation dans lc réticulum cndoplasmique, par les molécules du $\mathrm{CMH}$ de classe I [9]. Sclon une équipc de Stockholm (Suède), cette translocation scmble sc faire indépendamment de l'ATP, alors que cette molécule riche en énergic serait nécessaire à la constitution du complexe entre la molécule de classc I, le pcptide et la $\beta 2$-microglobuline [10]. Plusieurs équipes de l'université Harvard (Cambridgc, MA, USA) vicnnent de confirmer que ces peptides sont très petits, composés de huit à ncuf acides aminés dont les extrémités $\mathrm{N}$. ct $\mathrm{C}$. terminales sont parfaitement homogèncs. Il semble qu'ils soient profondément enfouis dans le sillon des molécules de classe I au scin duquel lcurs extrémités scraicnt parfaitement protégées. Cettc liaison, indispensablc à la

molécule de classe I et la $\beta 2$-microglobuline, est très stable $[11$, 12]. Un résultat remarquable est que les trois catégories de gènes concourant à la présentation de peptides par des moléculcs de classe I (figure 1), les gènes HLA, ceux des transporteurs et des protéases des protéasomes, scmblent répondre positivement et de façon coordonnée à l'interféron $\gamma$. Un autre résultat passionnant de ces études est que les peptides (figure 2) élués de moléculcs alléliques données de classe I (HLA-B27) sont en nombre limité. Les nonamères élućs des molécules HLAB27 par l'équipe de D. C. Wilcy [11, 12] correspondent, pour la moitié d'entre cux, à des protéines cytosoliques ou nucléaircs abondantes (histones, protéine de choc thermique, protéine ribosomique, factcur d'ćlongation). En fait, ce résultat pourrait être lié au fait que seuls les peptides dérivés de protéines abondantes peuvent sc licr à un nombre suffisant de molécules de classe I pour être détectés comme des pics distincts dans les éluats. La comparaison des séquences des peptides liés à HLA-B27 ne montre qu'unc caractéristique commune : la présence, en position 2, d'unc argininc, les huit autres positions étant plus diverses, non sélcctives pour cinq d'entre clles, partiellement sélectives pour les trois autres. De ces résultats, on pcut calculer qu'unc molécule de classe I pourrait peut-ĉtre présenter jusqu'à 13 millions de peptides différents si toutes les positions ćtaient indépendantes les unes des autres. Les peptides lićs dans le sillon des moléculcs de classe I scmblent ctrc dans une conformation ćtirće (chaîne $\beta$ ) contractant des interactions particulières avec la molécule de classe I au niveau des deux extrémités et des quatre positions plus ou moins spécifiques.

Une équipe de New Haven (CT, USA) vient maintenant de caractériser des peptides lićs aux molécules de classe II [13]. On sait [3] que ces peptides sc lient aux moléculcs de classe II au nivcau d'un compartiment endocytique et que la liaison du peptide à la molécule de classe II cst probablement assez lâche. Il est d'aillcurs possible de trouver, à la membrane, des molécules de classe II vides [3, 14]. Les peptides ligands de ces molécules sont plus grands que ccux se liant aux molécules de classe I : ils font 13 à 17 acides aminćs, l'extrémité N-terminale semblant bien déterminéc, alors que l'extrémité C-terminale est microhétćrogène pour un peptide donnć. Ccla laisse supposer que lc pcptide pourrait déborder du sillon de la moléculc de classe II par son extrémité carboxyterminale, qui pourrait rester sensible à unc dégradation protéolytiquc. La comparaison de trois peptides présentés par les molécules de classe II ct séquencés par le groupe de New Haven indique qu'ils n'ont aucune similitude. Ce résultat, qu'il conviendrait de confirmer par la comparaison d'un beaucoup plus grand nombre de pcptides, pourrait avoir d'importantes implications. Le contraste cntre une certaine spécificité des molécules de classe I et la très faible spécificité apparente des molécules de classe II pourrait, en effet, être rapproché des fonctions respectives des uncs et des autres : les premières vont jouer un rôlc dans l'immunité antivirale et dans toutc situation où des protéines étrangères sont synthétisées dans les cellules de l'hôte ; il suffit qu'un petit nombre de peptides issus de ces agents ćtrangers soit prćsenté pour que se développc la réaction cytotoxique éliminant la cellule infectéc. En revanche, les molécules de classe II interviennent dans la réponse anticorps à un antigènc protéique donné, au sein duquel un peptide présentable doit absolument ĉtre trouvé, cc qui exige de n'être pas 


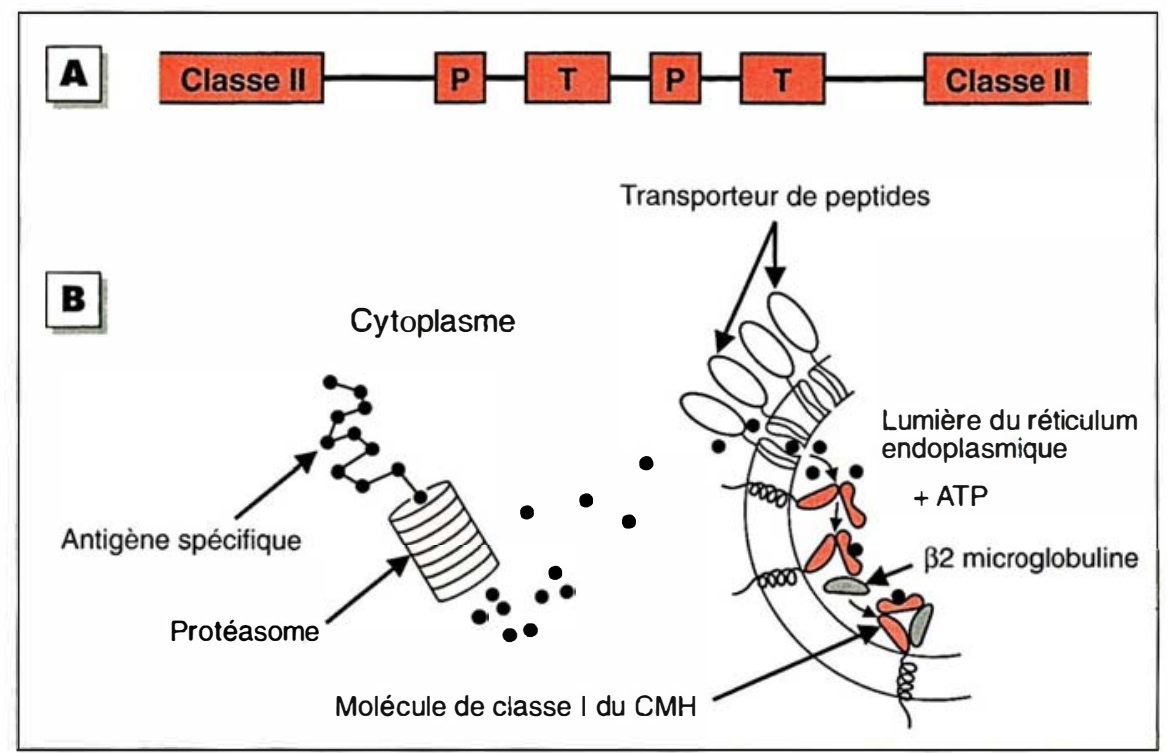

Figure 1. Relation entre protéasomes, transporteurs de peptides et molécules du CMH de classe I.

(A) Position des gènes de molécules de classe II, de composants du protéasome $(P)$ et de transporteurs (T). (B) Un antigène intact est dégradé par le complexe protéolytique multimoléculaire, dénommé protéasome, en peptides qui sont transportés, en l'absence d'ATP, dans la lumière du réticulum endoplasmique. Là, ces peptides se lient à une molécule de classe l, provoquant, en présence d'ATP, un changement conformationnel permettant la formation du complexe avec la chaine invariante $\beta 2$-microglobuline. C'est ce complexe qui sera ensuite transloqué à la membrane plasmique. (D'après [10].)

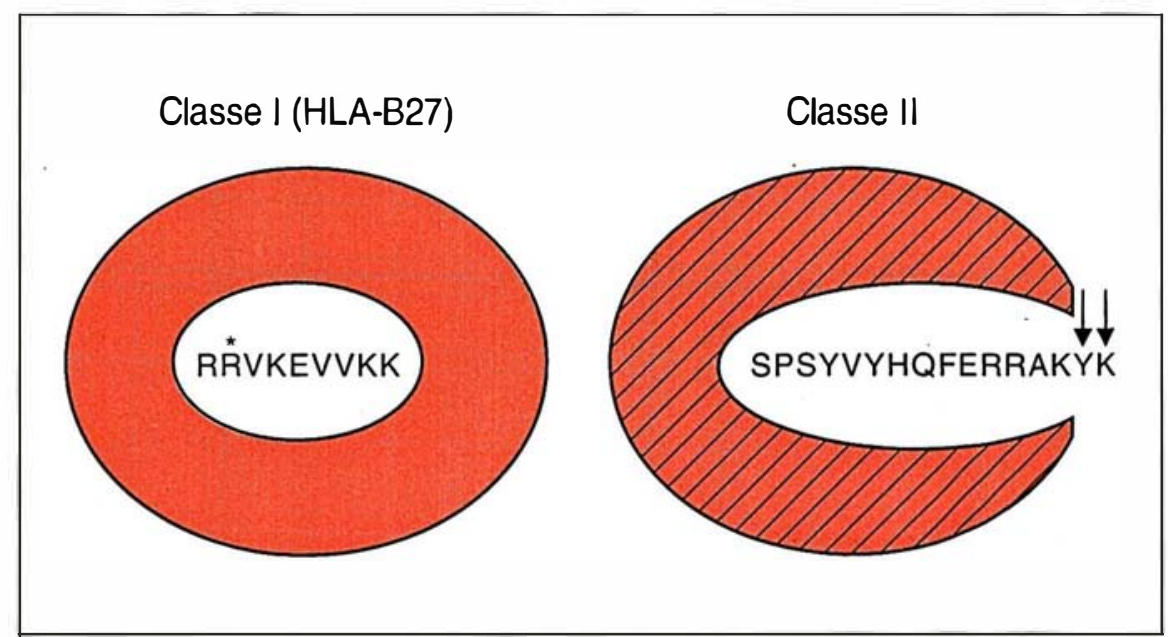

Figure 2. Différences entre la nature et le positionnement des peptides présentés par des molécules du CMH de classe I (HLA-B27) et de classe II. Les peptides présentés par HLA-B27 sont des nonamères ayant une arginine en deuxième position et dont les deux extrémités sont enfouies dans la molécule. En revanche, seule l'extrémité $\mathrm{N}$-terminale des peptides présentés par les molécules de classe II est en contact étroit avec la protéine. II existe très peu de spécificité aux autres positions. L'extrémité C-terminale "dépasse " de la protéine et peut donc être "rabotée " par une carboxypeptidase. Les peptides sont ici plus longs que dans le cas précédent. (D'après [13].) trop regardant sur la séquence du peptide présenté. Le petit nombre de peptides du self détectés dans l'éluat des molécules de classe II pourrait ne pas résulter d'une spécificité étroite de ces molécules, mais plus probablement de l'abondance et de la biodisponibilité des protéines dont sont issus les peptides. Une de ces protéines est la sousunité $\alpha$ de la molécule I-E du CMH de classe II dont un peptide est abondant dans les éluats caractérisés par l'équipe de C. A. Janeway [13]. Rudensky et al., de cette même équipe, ont utilisé un anticorps monoclonal dirigé contre le peptide I-E présenté dans le contexte de la molécule I-A ${ }^{b}$ et ont démontré la liaison de cet anticorps à un grand nombre de cellules présentatrices d'antigène, confirmant qu'il s'agit là d'un peptide du soi tout à fait dominant [15]. Dans le thymus, cet anticorps reconnaît les cellules thymiques responsables de la délétion clonale des lymphocytes $\mathrm{T}$ autoréactifs, mais non les cellules corticales intervenant dans la sélection positive des thymocytes exprimant des molécules du $\mathrm{CMH} \mathrm{du}$ self $\left(\mathrm{m} / \mathrm{s}\right.$, suppl. au $n^{\circ} 1$, vol. 5, p. 25, et $n^{\circ}$ 10, vol. 5, p. 788). Ce résultat pourrait signifier que les molécules du $\mathrm{CMH}$ reconnues au stade de la sélection positive, soit ne sont pas liées à un peptide du self, soit, plus probablement, sont liées à des peptides spécifiques, différents de ceux présentés au stade de la sélection négative par délétion clonale

Axel Kahn RÉFÉRENCES

1. Kourilsky P. Le soi peptidique. médecine/sciences $1988 ; 4$ : 177-83.

2. Claverie JM. Immunologie 1989 : la révolution peptidique. médecine/sciences $1990: 6$ : 367-77.

3. Rabourdin-Combc C, Bertolino P, CaliLaurens V, Gerlier D. La présentation de l'antigc̀ne aux lymphocytes $T$. médecine/science 1991; 7 : 674-80.

4. Glynnc R, Powis SH, Beck S, Kelly A, Kerr LA, Trowsdale J. A proteasome-rclated gene between the two $\mathrm{ABC}$ transporter loci in the class II region of the human MHC. Nature 1991; 353 : 357-60.

5. Ortiz-Navarretc V, Seelig A, Gernold $M$, Frendzel S, Kloctzel TM, Hämmerling GJ Subunit of the $20 \mathrm{~S}$ proteasome (multicatalytic protcinase) encoded by the major histocompatibility complex. Nature $1991 ; 353: 662-4$ 


\section{RÉFÉRENCES}

6. Brown MG, Driscoll J, Monaco JJ. Structural and scrological similarity of MHC-linked LMP and proteasome (multicatalytic proteinasc) complexes. Nature $1991 ; 353: 355-7$.

7. Martinez CK, Monaco JJ. Homology of proteasome subunits to major histocompability complex-linked LMT genc. Nature 1991; 353 : 664-7.

8. Kelly A, Powis SH, Glynne R, Radlcy E, Beck S, Trowsdalc J. Sccond proteasomcrelated gene in the human MHC class II region. Nature $1991 ; 353$ : 667-8.

9. Robertson M. Antigen processing : protcasomes in the pathway. Nature $1991 ; 353$ : 300-1.

10. Lévy F, Gabathuler R, Larsson R, Kuist $\mathrm{S}$. ATP is required for in vivo assembly of MHC class I antigen but not for transfer of peptides accross the EB membrane. Cell 1991 ; 67 : 265-74.

11. Jardetzky TS, Lane WS, Robinson RA, Madden DR, Wiley DC. Identification of self peptides bound to purified HLA-B27. Nature 1991; $353: 326-9$.

12. Madden DR, Gorga JC, Stromingen JL, Wiley DC. The structure of HLA-B27 reveals nonamer self peptides bound in an extended conformation. Nature $1991 ; 353: 321-5$.

13. Rudensky AE, Preston-Hulburt P, Hong SS, Barlow A, Jancway A. Sequence analysis of peptides bounds to MHC class II molccules. Nature 1991 ; 353 : 622-7.

14. Germain RN. Antigen presentation : the sccond class story. Nature 1991 ; 353 : 605-6. 15. Rudensky AY, Rath S, Preston-Hurlburt P, Murphy DD, Jancway CA. On the complexity of sclf. Nature $1991 ; 353: 660-2$.

\section{TIRÉS A PART}

A. Kahn.

\section{AVIS AUX AUTEURS DE TRAVAUX IMPORTANTS}

$\mathrm{m} / \mathrm{s}$ propose aux auteurs de travaux importants, publiés dans des revues d'audience internationale et de premier niveau, de présenter leurs résultats sous forme de brève, de nouvelle, voire de mini-synthèse, au mieux publiés dans médecine/sciences parallèlement à l'article princeps.

\section{LA RÉDACTION}

Les momuscrits doivent être adressés $\dot{a}$ : médecine/sciences, 6, rue Blanche, 92120 Montrouge, France.

Tel. : (1) 47.35.85.52

Fax : 46.57.10.09 